\title{
Notas sobre a democracia econômica
}

\section{Notes on economic democracy}

\author{
Pompilio Locks Filho \\ Doutorando em Ciência Política pela Universidade Federal ao Rio Grande do Sul (UFRGS) \\ lockspompilio@gmail.com
}

\begin{abstract}
Resumo: Enquanto se prolifera a literatura que trata dos aspectos formais da democracia política, buscamos neste trabalho compreender um tema negligenciado do ponto de vista teórico: a democracia econômica. Vinculada ao desenvolvimento do capitalismo, essa reivindicação perpassa duzentos anos de história das ideias e é um tema importante de aprofundamento para as teorias políticas contemporâneas. Por meio de levantamento bibliográfico, trazemos uma reflexão sobre os principais temas e autores que lidaram com a democracia no âmbito econômico, finalizando com algumas indicações sobre as mutações que a ideia sofreu ao longo do tempo.
\end{abstract}

Palavras-chave: Democracia. Economia. Pensamento político. Capitalismo. Trabalho.

\begin{abstract}
While proliferates the literature dealing with the formal aspects of political democracy, we seek in this work understand a neglected theme from a theoretical point of view: the economic democracy. Linked to the capitalism development these claims go beyond two hundred years in the history of ideas and is a major theme for contemporary political theories deepening. Trough literature, we bring a reflection on the main themes and authors who have work with the democracy in economy, ending with some indications about the changes in the idea over time.
\end{abstract}

Keywords: Democracy. Economy. Political Thought. Capitalism. Labor.

Originais recebidos em: 11/05/2015

Aceito para publicação em: 25/08/2015

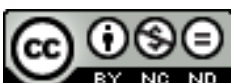

ste trabalho está licenciado sob uma Licença Creative Commons Atribuição-Uso NãoComercial-Vedada a criação de obras derivadas 3.0 Unported License. 


\section{Introdução}

Por um lado, a queda do muro de Berlim representou o colapso do socialismo soviético e a crise teórica das correntes de esquerda. Por outro, se dá o apogeu da doutrina liberal de democracia representativa e do capitalismo de livre mercado, como um modelo hegemônico no mundo globalizado (Santos, 2002). Em seu plano político, esse modelo se assemelha ao mercado econômico e possui algumas características básicas (Bobbio, 1995): a garantia de direitos políticos, ou seja, de expressar sua própria opinião e de escolher representantes, o voto de igual peso prevalecendo regra da maioria, a concorrência entre partidos com projetos diferentes, a liberdade de imprensa e de organização social, a autonomia entre os poderes executivo, legislativo e judiciário e, por último, que nenhuma decisão tomada pela maioria limite os direitos da minoria.

Podemos identificar o fio condutor deste modelo de democracia, que percorre a Idade Média com Santo Agostinho e São Tomás de Aquino, a Idade Moderna com Maquiavel, Hobbes e Locke e, enfim, a Idade Contemporânea com Bentham, Madison e James Mill. Chegamos ao século XX com sua expressão maior em autores como Schumpeter, Bobbio, Sartori e Dahl (Held, 1996) ${ }^{1}$. Embora com diferenças substanciais entre esses autores, essencialmente no que se refere ao papel da sociedade civil, grande parte considera que a forma mais factível de democracia acontece através do voto periódico, da distinção entre governantes e eleitores, no respeito às regras do jogo e na estabilidade do sistema, conforme aponta Sartori (2003, p.27-28), “democracia sin adjetivos se entiende como democracia política. Entre ésta y las otras democracias, la diferencia es que la democracia política es supra-ordenada y condicionante, y las otras son subordinadas y condicionadas."

No entanto, além das constantes crises pelas quais as democracias ocidentais passaram com a ascensão de projetos totalitários e autoritários, atualmente as recentes ondas de manifestações anti-sistêmicas, bem como a apatia e desconfiança com os partidos políticos e governos, a ampliação e perpetuação das desigualdades sociais mostram que, de fato, esse modelo de democracia sofre de algumas carências inerentes ao seu próprio projeto (Lefort, 1991; Castoriadis, 2001). Não que as regras do jogo político-institucional não sejam importantes, mas também é preciso vislumbrar a democracia e o poder para além da questão formal, uma vez que o Estado é o reflexo de

\footnotetext{
1 Também chamada de "protetiva" (Held, 1996), visto que seu principal tema está em proteger as liberdades individuais de qualquer despotismo, bem como livrar a civilização ocidental de qualquer espécie de instabilidade política.
}

Em Debat: Rev. Dig., ISSNe 1980-3532, Florianópolis, n. 12, p. 159-181, jul-dez, 2014. 
todo o corpo social (Lefort, 1991) e a democracia contemporânea, como um processo historicamente definido, deve ser compreendida nos marcos do capitalismo e do consumo que constroem o indivíduo político (Castoriadis, 2001; Santos e Avritzer, 2002). O importante nesse contexto é ter um cidadão consumidor e não um cidadão politicamente ativo.

Tendo em vista esses aspectos, nesse trabalho procuramos recuperar uma problemática tratada pelos principais teóricos contemporâneos, mas que cada vez menos é abordada: a democracia econômica. Em fins do século XX, tanto Carole Pateman (1970), quanto Robert Dahl (1985), renomados cientistas políticos, apontaram a escassa discussão sobre o tema, mesmo que as propostas de democracia econômica tenham uma larga histórica dentro do pensamento ocidental. Ao mesmo tempo, pesquisas relativamente recentes, como a de Almond e Verba (1963), constataram que as estruturas de autoridade dentro do local de trabalho são, provavelmente, as mais significativas em que um homem se encontra em contato diário. As oportunidades de participar das decisões no âmbito econômico são essenciais para a transição de uma sensação de passividade política, para uma sensação de eficiência política.

Deste modo, abordamos e analisamos algumas concepções sobre a democracia na economia, especificamente no ambiente de trabalho e nas empresas. Estamos cientes das diferentes abordagens que poderíamos realizar e também da inviabilidade de realizar todas as tarefas simultaneamente; tivemos que optar por caminhos segundo nossos interesses, de modo a responder as questões que desejamos. Como argumenta o historiador dos conceitos Reinhart Koselleck (1993), os diversos focos são igualmente legítimos e implicam pesquisas factíveis de diversos níveis, em uma análise na qual se pode passar do conceito ao parágrafo, daí ao livro, ao debate político e social, à linguagem ordinária, à relação com os demais conceitos e assim sucessivamente, em um trabalho de pesquisa infindável.

Do ponto de vista metodológico realizamos um levantamento crítico da bibliografia, ora por meio de análises já realizadas, ora através de fontes primárias, quando as referências forem escassas. Mesmo que qualquer seleção de autores seja excludente, na medida em que deixa de lado inúmeras outras possibilidades de análise do fenômeno, iniciamos com a problemática do cooperativismo, presente no século XIX e passamos para o tema dos conselhos operários no início do século $\mathrm{XX}^{2}$. Em seguida,

\footnotetext{
${ }^{2}$ Entre as principais exclusões, apontamos o anarcossindicalismo, do final do XIX, e o pluralismo, do início do século XX.

Em Debat: Rev. Dig., ISSNe 1980-3532, Florianópolis, n. 12, p. 159-181, jul-dez, 2014.
} 
analisamos os teóricos autogestionários do pós-guerra e finalizamos com os trabalhos de Carole Pateman e Robert $\mathrm{Dahl}^{3}$. Com esse levantamento pretendemos tão somente iniciar uma análise e compreender as ideias aglutinadas em torno do tema da democracia econômica desde um ponto de vista historicamente orientado.

\section{Uma gênese da democracia no âmbito econômico}

É importante constatar que as primeiras formulações sobre possibilidades de projetos democráticos dentro da esfera econômica surgiram logo no início do capitalismo industrial, com o advento da Revolução Industrial. A separação entre o operário e os meios de produção, a existência de um único proprietário, a busca pela lucratividade e pelo desenvolvimento econômico submeteram e submetem o trabalhador a um grau cada vez maior de hierarquização, no qual se cria todo um corpo de supervisores e mestres para controlar a produção, e assim garantir o aumento da oferta de mercadorias e conseqüentemente da lucratividade.

De acordo com Merlo e Lapis (2007) na primeira fase do capitalismo, o controle exercido sobre os trabalhadores expressava-se da forma mais autoritária possível. O despotismo fabril materializava-se em agressões físicas, ameaças, castigos, multas e demissões. Intensificou-se o trabalho em condições precárias, por longas jornadas - de 12 a 15 horas diárias - e por baixos salários. Mesmo com resistências pontuais por parte dos trabalhadores, todos estes fatores levaram a uma maior subordinação do operário à autoridade no universo fabril, ou seja, à maior concentração de decisões nas mãos da direção, e ao divórcio entre o trabalho intelectual e o trabalho manual ${ }^{4}$.

Neste contexto, o antigo trabalhador manufatureiro cujos meios de sobrevivência o ligavam mais intimamente ao objeto de seu trabalho e cujas decisões em grande parte eram tomadas de maneira mais autônoma, de acordo com as necessidades latentes, vê-se despojado de responsabilidades inerentes ao processo de produção como um todo, ligado, a partir de então, às responsabilidades triviais relativas o maquinário (MERLO; LAPIS, 2007). A essência da gestão nas empresas modernas se estabelece na dualidade entre o que gere e o que é gerido; entre o que organiza, comanda e controla, e o que executa, sendo, portanto, organizado, comandado e controlado, separando dois aspectos

\footnotetext{
3 Acreditamos que os autores selecionados trazem questões importantes de maneira coerente para as questões da democracia econômica. Além do mais, se configuram em autores de referência no debate político contemporâneo.

4 Estes fatores começaram a ser estudados a partir da década de 1960 pela sociologia do trabalho (FRIEDMANN; NAVILLE, 1962).
}

Em Debat: Rev. Dig., ISSNe 1980-3532, Florianópolis, n. 12, p. 159-181, jul-dez, 2014. 
indissoluvelmente ligados do trabalho humano: concepção e execução. Nesse sentido, o trabalho configura-se em uma visão unidimensional da realidade social, pois traduz a incapacidade de ver o agente social enquanto ser complexo e o limita a funções univalentes no processo produtivo (MOTTA, 1981).

Pelos debates travados na época, podemos ver que na medida em que o capitalismo se consolidava, idéias contrárias a este se proliferavam, entre as quais destacamos os socialistas utópicos no início do século XIX. Entre os primeiros, Robert Owen (1771-1858) é considerado um dos fundadores do movimento cooperativo que inspirou grande parte dos socialistas da metade do século XIX. Em New Lanark fundou a primeira cooperativa existente, e muitas outras cooperativas surgiram na Inglaterra neste período devido as suas idéias expressas no livro Report to the County of New Lanark, de 1820. Cabe ressaltar que no início do século XIX, o movimento cooperativo, no seu sentido amplo, e o movimento socialista eram próximos e, às vezes, chegavam a se confundir. A palavra "cooperação" foi usada a primeira vez por Robert Owen em 1821, no sentido oposto à "concorrência" e como sinônimo de "socialismo", e, até mesmo de "comunismo" (SECCO, 2003).

Crítico do trabalho alienante, para Owen o principal obstáculo na constituição de uma sociedade cooperativa era o individualismo crescente e a divisão do trabalho que foram acentuados pela revolução industrial. Como solução, propunha uma socialização gradual dos meios de produção que seria articulada com uma burocracia estatal centralizadora, responsável pela tributação das empresas. Segundo Owen, não deveria haver representação nas cooperativas, somente a intervenção direta dos trabalhadores em todos os assuntos, que seria dividida em um setor interno, responsável pela produção, pela distribuição e pela educação dos cooperados, e em um plano externo, a comunicação, a troca de excedentes, a distribuição dos "inventos" e a fundação de outras comunidades. No lugar do Estado, deveria haver uma comissão composta pelos delegados dos setores externos das diferentes empresas que se encarregariam em delegar a favor de uma sociedade planificada (TSUZUKI, 1992).

Dentre as críticas dirigidas a Owen, destacamos a falta do questionamento dos dispositivos de hierarquização e reprodução das desigualdades, que são o centro da questão de autores como Proudhon, Fourier e Marx. Embora suas ideias sobre o cooperativismo tenham sido inovadoras, algumas questões pertinentes ficaram abertas para o debate contemporâneo. Em primeiro lugar, o sistema cooperativo, por si só, seria capaz de alterar as estruturas da sociedade com um estado burocrático e centralizado? E 
até que ponto as estruturas cooperativas funcionariam de acordo com princípios de democracia direta em uma sociedade competitiva e hierarquizada, dependente de resultados econômicos?

Fourier (1772-1837), crítico de Owen, considerava o sonho cooperativista nãocientífico e ingênuo. Ao mesmo tempo em que Fourier buscava a fundamentação de um "socialismo científico", estava empenhado, como Owen, em avaliar as causas que haviam levado à civilização ao estado deplorável de sua época. Sem entrar especificamente na questão da gestão operária em empresas, ou seja, nos problemas do cooperativismo como Owen havia feito, Fourier em sua obra O Novo Mundo Industrial e Societário de 1829, formulou o que seria chamado de "Falanstério": uma colônia imaginária de 400 hectares e com 400 famílias, na qual iria surgir uma democracia societária onde "a associação seria segundo as semelhanças [...] e o trabalho não é mais sob coação, onde cada um realiza nele seus próprios gostos." (CHATELET; DUHAMEL, 1985, p.146).

Para Konder (1968), esse é o "socialismo do prazer", pois surge de um ódio pelo comércio, pelos mecanismos industriais, pelo sistema representativo e pela suposta separação de poderes. Fourier rejeitava qualquer forma de coerção presente na sociedade burguesa, seja na família, na educação ou na sexualidade (CHATELET; DUHAMEL, 1985). Para Albornoz (2007), o mundo sócio-econômico idealizado por Fourier buscava superar a indústria em seu sentido mais estrito, pois com o aperfeiçoamento das relações humanas para além das relações de poder também emerge um aperfeiçoamento da organização do trabalho, na qual as paixões deveriam estar mais presentes. Fourier foi, sobretudo, um homem do século XIX que, naquele momento do desenvolvimento econômico e científico, batalhava pela transformação do trabalho em algo de belo e prazeroso.

Por sua vez, Saint-Simon (1760-1825) entendia como inevitável o desenvolvimento rumo a uma produção industrial em grande escala e não reivindicava o retorno a uma sociedade tradicional como grande parte dos pensadores do século XIX. No entanto, não analisou com profundidade os conflitos de classe que surgiam na sociedade contemporânea, defendendo um planejamento conjunto entre capitalistas industriais e trabalhadores contra os que, a seu ver, eram não-produtores parasitários. Ainda que fizesse uma árdua crítica aos economistas clássicos do Laissez-Faire, denunciando as desigualdades sociais, possuía uma enorme admiração pelos industriais, responsáveis pelos progressos desenvolvidos na civilização europeia. 
Na obra El Organizador, escrita em 1819, o autor elaborou seu primeiro plano para constituir um "parlamento industrial" que, em suma, seria constituído por três Câmaras Parlamentares, o reflexo das três principais classes sociais contemporâneas. A primeira seria a Câmara das Invenções que seria composta por 300 membros, entre artistas, engenheiros civis, poetas, artistas, arquitetos e músicos, cujas funções estariam centradas na construção e no planejamento de obras públicas. A segunda Câmara teria 300 membros com formação de matemática e física, cuja função teria como foco fiscalizar e examinar a viabilidade da primeira Câmara, por isso o seu nome Câmara de Exames. A terceira Câmara seria a de execução e representaria cada um dos setores da indústria, com o objetivo de arrecadar impostos e aprovar os programas revisados pela segunda Câmara (RIQUELME, 2009).

Saint-Simon teorizou uma revolução social que concedia poder aos industriais, termo correlato a empresários, os financistas, mas também operários especializados, os agricultores e artesãos; de modo que se eliminasse a classe política, considerada como inútil (CHATELET; DUHAMEL, 1985). Seu novo sistema político-social sugeria que a propriedade privada respeitasse os interesses coletivos, que o salário dos trabalhadores fosse vinculado a sua produtividade e que o direito a herança fosse abolido. Enquanto Fourier e Owen tinham a idéia de que para a solução das questões sociais bastava fundar pequenos grupos fechados com propósitos contra-hegemônicos que empregariam toda a força de trabalho de seus membros (Secco, 2003), Saint-Simon e seus seguidores, em contraposição, defendiam a "estatização" ou o "coletivismo estatal" de todas as esferas econômicas submetidas às Câmaras descritas anteriormente. Contudo, segundo Abendroth (1977) tanto Owen, quanto Fourier e Saint-Simon imaginavam uma futura sociedade onde haveria uma linda harmonia entre classes dirigentes e dirigidas sem qualquer tipo de conflito.

Alguns anos depois dessas publicações, Paris já vivia um intercâmbio de idéias maior do que em qualquer outro período até então. Era uma grande fase para o pensamento radical francês, "e o socialismo estava se tornando quase moda nos círculos literários parisienses. Nos quatro anos anteriores a 1843, nada menos de oito autores haviam publicados ataques surpreendentes ao capitalismo." (JACKSON, 1963, p.42). Neste contexto, o pensamento de Proudhon (1809-1865) foi de grande influência e, segundo Abendroth (1977), seu mérito está em romper com as concepções socialistas de Owen, Fourier e Saint-Simon nas quais não haveria conflitos entre classes. 
Para Proudhon, a política estava assentada sobre relações sociais legitimadas, primordialmente pelas forças econômicas, de modo que não bastariam introduzir reformas políticas e sociais moderadas. Somente com a alteração radical das relações sócio-econômicas poderiam ocorrer mudanças na sociedade capitalista, já que considerava a produção de bens econômicos o resultado de uma gama de trabalhos e de aptidões tão diversas que um homem sozinho nunca poderia suprir. A atividade de produção é resultado da cooperação e o produto coletivo que os trabalhadores criaram e a soma individual que lhes foi paga é que o lucro do capital encontra sua explicação ${ }^{5}$. Como solução, sugere um autogoverno, no qual o poder decisório se desloque para as mãos dos próprios trabalhadores, minimizando os traços autoritários dentro das instituições.

Já na esfera política, profetizava que tanto um governo estabelecido sob uma monarquia despótica quanto uma democracia com representantes eleitos não pode realizar-se na pureza de seu ideal de representação, pois um estado, qualquer seja a forma que assuma, enquanto não se tornar um órgão submetido a uma sociedade de iguais, será para o povo uma condenação. Como constatação lógica, os instrumentos da revolução para esta nova sociedade devem ser procurados na reorganização econômica da sociedade. Nesse sentido, a proposta de democracia econômica em Proudhon, construída no seu livro Idéia Geral da Revolução no século XIX, de 1851, pode ser resumida através do conceito de mutualismo nas relações econômicas, em empresas totalmente socializadas, e do conceito de federalismo, baseado em relações políticas piramidais de representação. Mas para isto acontecer, a propriedade deve ser federativa, um direito absoluto de todos (MOTTA, 1981). ${ }^{6}$

Atento leitor e crítico de seus antecessores, chamados por ele de utópicos, para Karl Marx (1818 - 1883) a democracia posta no campo econômico através do cooperativismo foi visualizada apenas como uma forma de transição entre a economia política da burguesia e a economia política do proletariado (MASSARI, 1977). Dessa forma, não condenava de antemão a idéia de indústrias socializadas, mas criticava uma visão ingênua do cooperativismo feita pelos socialistas utópicos, cuja crença residia em uma transformação gradual da sociedade capitalista por meio das cooperativas. Nesse sentido, em seu pensamento não há um exame e uma reflexão pormenorizada sobre as

\footnotetext{
${ }^{5}$ Anos após, Karl Marx aprimorará esta formulação e irá denominá-la de mais valia.

${ }^{6}$ Esta discussão, que já aparece em Proudhon, será retomada adiante com as problematizações de Robert Dahl sobre a propriedade.
} 
cooperativas, mas sim, uma reflexão sobre a força que estas possuíam para emancipação da classe trabalhadora.

Duvidava da capacidade do cooperativismo de derrotar monopólios, porque o principio do capitalismo e da lógica do capital continuava o mesmo nas fábricas socializadas, só que amenizado, pois os associados tornavam-se seus próprios capitalistas. O interesse de Marx pelo fenômeno cooperativista residia na representação de elementos de uma nova estrutura social em gestação, visto que sua interpretação teórica do capitalismo como modo de produção histórico vislumbrava outro movimento, só que na direção da sua superação. Essas fábricas mostravam, portanto, como ao chegar a uma determinada fase de desenvolvimento das forças materiais, poderia nascer e se desenvolver naturalmente um modo de produção totalmente novo.

Em um discurso na Associação Internacional dos Trabalhadores, em 1865, Marx (2004) considerou a característica mais relevante das fábricas cooperativas o fato de que demonstraram que a produção em grande escala podia ser realizada sem a existência de uma classe de patrões e que os meios do trabalho não precisam ser monopolizados, dominando e explorando o operário, pois o trabalho assalariado é apenas uma forma social transitória e inferior, destinada a desaparecer diante do trabalho associado. Contudo, essa avaliação positiva não levou Marx a ignorar o quadro global em que as fábricas-cooperativas estão imersas, caracterizado pela subjugação dos trabalhadores aos capitalistas. Marx (2004) acreditava que o sistema cooperativista jamais iria transformar a sociedade capitalista, uma vez que são necessárias mudanças sociais mais amplas, realizadas somente através da transferência do poder estatal aos próprios trabalhadores.

\section{Os conselhos operários no início do século $\mathrm{XX}$}

O início do século XX caracterizou-se como um momento de efervescência do pensamento político contemporâneo que ressignificou os principais debates ocorridos durante o século XIX. Nesse sentido, o conceito de conselhos operários começa a ganhar expressão a partir da década de 1920 entre os comunistas dos conselhos (Paul Matick, Karl Korsh, Anton Pannekoek, etc.) e entre o comunismo italiano, especialmente, com o grupo da revista L'Ordine Nuovo (LON), na Itália, capitaneado por Antonio Gramsci (1892-1937) (SECCO, 2003). Para a emergência da teoria dos conselhos costumam-se citar dois principais fatores: em primeiro lugar, na Itália, no ano de 1904, o surgimento das comissões internas nas fábricas, que transitaram, com o 
tempo, da negociação contratual à pretensão da gestão direta da produção. Estas comissões internas resultaram em 1919 e 1920 em algumas ocupações, sem sucesso, de fábricas em Turín com mobilização dos conselhos de fábrica e do Partido Socialismo Italiano. Concomitante, em 1905, aparece o primeiro soviete - traduzido como conselho - na Rússia. Tratava-se de um conselho com funções exteriores à produção e a esfera econômica, sendo, portanto, mais abrangente em suas reivindicações societárias, pois estava aberto à participação qualquer cidadão. Algum tempo depois, a Revolução Russa também difundiu a idéia, fossem no interior das fábricas ou com funções especificamente políticas (SECCO, 2003), inaugurando uma série de debates no campo da esquerda sobre o futuro da Revolução Russa caso tivesse aderido à teoria e a prática dos conselhos. Desse modo, temos que estes conselhos surgem, principalmente, de uma crítica aos rumos marxistas-leninistas que estava tomando a Revolução Russa.

De acordo com a literatura pesquisada, o conselhismo terá como seus principais formuladores Antonio Gramsci e Anton Pannekoek, a partir das críticas ao potencial revolucionário dos sindicatos burocratizados e do movimento cooperativo. Gramsci se tornou o mais importante pensador marxista de sua geração, embora só depois da Segunda Guerra Mundial (1939-1945) foi de fato reconhecido. Diante da timidez política dos sindicatos e do Partido Socialista Italiano, Gramsci se convenceu da necessidade de superar essas estruturas tradicionais através de instrumentos de autogoverno operário, inspirados numa visão idealizada do soviete russo (Agosti, 1999). A expressão italiana mais conhecida entre os trabalhadores, comissioni interne, traduzida habitualmente como comitês de fábrica, foi por ele designada como um novo tipo de organização revolucionária, de modo que sua força consistia em unir à própria consciência da massa operária e ao mesmo tempo interagir com equilíbrio entre sindicatos e partidos (GRAMSCI, 1990).

Contudo, mesmo com uma visão conciliadora, reconhecia os limites do sindicato e sua impossibilidade de se transformar em um instrumento radical de renovação da sociedade. Destas problematizações Gramsci (1976) irá teorizar sobre a possibilidade de democracia no campo econômico, visualizando um organismo que se baseia numa relação diferente com a experiência de fábrica em um sistema democrático de consenso e de representação direta, superando os limites tradicionais do sindicato. A importância dos Conselhos Operários reside, portanto, no fato que "o trabalho, depois de ter sido por séculos um instrumento nas mãos dos que o exploravam pretende afirmar-se hoje, dirigir a si mesmo" (GRAMSCI, 1976, p.46). A democracia operária, no pensamento 
gramsciniano, é pressuposto para constituição de relações sociais de produção que mantém como horizonte a igualdade entre os seres humanos e o fim da alienação.

Com o desenvolvimento de sua obra, Gramsci formulou a questão da hegemonia, baseada na necessidade da tomada de conhecimento das classes oprimidas de sua própria condição para que seus interesses de classe se voltem para o plano do político, naquilo que Coutinho (1994) conceitua como "guerras de posições". De acordo com essa concepção revolucionária, algumas tarefas dos conselhos de fábricas seriam supervisionar a administração para que as empresas não deslizem para uma tecnocracia, demitir empregados que se mostrem inimigos da classe trabalhadora, lutar pela conquista de direitos e liberdade, bem como controlar a produção da empresa. Mas, além disto, a principal atividade dos conselhos seria dirigir movimentos de massa contra a ordem capitalista, educando a classe trabalhadora para a luta revolucionária e para a criação do futuro estado proletário (GRAMSCI, 1920). Nesta perspectiva, os conselhos aparecem imbricados nas duas dimensões que, até então, apareciam desvinculadas nas teorizações socialistas: a economia e a política (HAIDAR, 2010).

Por outro lado, Anton Pannekoek (1873-1960), representante do socialismo alemão, negava a possibilidade de articulação entre os conselhos operários e qualquer estrutura verticalmente dirigida, porque se formaria "uma classe de funcionários, uma burocracia, que dispõe de todos os meios de poder e organização: dinheiro, imprensa, nomeação dos funcionários subalternos [...]" (PANNEKOEK, 1976, p.115). Segundo Nildo Viana (2005) e John Gerber (1989), Pannekoek foi quem mais se dedicou ao que ele denominava "novo movimento operário" e as especificidades dos conselhos.

Nesses conselhos operários, não haveria lugar para os dirigentes profissionais, mas somente delegados que levariam os interesses dos trabalhadores as instancias superiores de decisão, e seriam segundo Pannekoek uma 'correia de transmissão'. Estes trabalhadores que formariam os sovietes necessitariam ter uma consciência de classe e para isso seriam educados por uma elite revolucionária, responsável pela propagação das idéias conselhistas e pela formação de uma consciência de classe revolucionária. Para Pannekoek, só os trabalhadores poderiam participar do processo revolucionário e caberia a estes mobilizar o restante da sociedade ou renegá-los, caso não partilhassem da ideologia conselhista. Esta radicalização economicista pressupõe um ideal que não visa o poder político, mas sim o seu esvaziamento até o término dos conflitos de classe. Assim, segundo o autor (1976, p.15), "só o sistema de sovietes constitui a verdadeira democracia operária.”. 
Mesmo de forma romântica e utópica, o conselhismo de Pannekoek, fortemente menosprezado pelas correntes de pensamento socialistas (GERBER, 1989), irá influenciar os escritos de uma nova esquerda que surgirá baseada na idéia de autogoverno operário e de espontaneismo revolucionário e cuja forma de autoorganização inspirava-se no modelo embrionário da Comuna de Paris e nos estágios iniciais da Revolução Russa.

\section{As teorias autogestionárias}

A segunda guerra mundial e a ascensão do nazi-fascismo marcaram a crise do movimento operário e, por conseguinte, do comunismo conselhista. Este sobreviveria marginalmente na sociedade capitalista, através de publicações e da influência nas mais variadas correntes políticas que buscavam apresentar uma alternativa à socialdemocracia e ao bolchevismo. Portanto, foi somente a partir dos anos cinqüenta e sessenta que se operou uma retomada do debate sobre a intervenção operária na produção, aparecendo sob a égide do termo autogestão, para caracterizar a experiência iugoslava. O termo sérvio samoupravjie (samo significa o prefixo grego auto, e upravje significa gestão) foi traduzido ao francês por autogestion (GUILLERM; BOURDET, 1976) e começaram a surgir revistas como Socialismo ou Barbárie (1948-1967), organizada por Castoriadis e Lefort bem como a revista Socialismo e Autogestão, organizada por Yvon Bourdet (1966-1986). Estas foram disseminadoras deste novo movimento em prol de uma radicalização da democracia tanto na esfera econômica quanto na esfera política.

Além disto, também podemos apontar alguns outros elementos que propiciaram o desenvolvimento destas idéias; a globalização incipiente, a solidificação, mesmo abaixo de incessantes crises, do capitalismo financeiro, os sinais de fracasso do socialismo real colocando abaixo os pilares do marxismo/leninismo, junto de uma negação da burocratização vinculada à social-democracia. Nesse sentido, para um grupo de intelectuais extremamente radicalizados era preciso superar o burocratismo dos partidos e dos sindicatos renovando as propostas conselhistas. Novos experimentos de intervenção operária na produção pareceram indicar os elementos que superariam o sindicalismo, restrito à negociação do preço da força de trabalho, e o cooperativismo, cujos dirigentes estavam, em curto prazo, limitados a um horizonte de concorrência pacífica dentro do mercado capitalista. 
Neste contexto surge uma corrente de pensamento com objetivo de socializar o poder gerencial das empresas, atribuindo aos trabalhadores, através de seus delegados, o poder deliberativo em todas as decisões que lhe dizem respeito, superando a distinção entre quem toma as decisões e quem as executa no processo de organização do trabalho, instaurando, assim, uma plena democracia econômica. Complementando as características econômicas, mas possuindo uma estrutura diversa, articulam-se os pressupostos políticos. Segundo Follis (2001), há nestes uma definição mais clara do significado da autogestão, visto que os teóricos integraram-se, de maneira geral, à corrente de pensamento da democracia radical, de Rousseau à atual sociologia crítica. Nas esferas de participação, a transposição de um mecanismo representativo para o âmbito das estruturas concretas das várias atividades econômico-sociais, vislumbradas em comunidades locais, implica, em sua extrema conseqüência, na dissolução do poder econômico-político e no funcionamento das estruturas sociais só mediante autoridade socializada, alterando assim, uma realidade social mais ampla do que tão somente a produtiva.

$\mathrm{Na}$ tentativa de captar os conteúdos substanciais do conceito, nota-se que, visualizado sob o espectro econômico, baliza-se pela inversão de certos pressupostos que, desde meados do séc. XIX causam mal-estar na civilização ocidental e que também são tratados pelos diversos pensadores analisados neste texto. A propriedade privada, a divisão acentuada do trabalho, o desenvolvimento descontrolado da técnica e as empresas multi/transnacionais que se proliferaram de maneira intensa constituem, assim, eixos em torno dos quais se articula o discurso autogestionário cujas pretensões podem ser captadas nesta frase de Rosanvallon:

En el siglo XVIII el concepto de democracia canalizo y expresó las esperanzas revolucionarias. En el siglo XIX ese papel lo desempeño el concepto de socialismo. Nuestra tesis es que el concepto de autogestión está destinado a desempeñar el mismo papel que representaron en su día los de democracia y socialismo. (ROSANVALLON, 1979, p.18)

Charbonneau (1993) desenvolveu uma análise temporal mais minuciosa sobre o os pensamentos autogestionários, enfocando o surgimento do termo na França durante a década de 1960 e seu desuso por volta de 1980. Ressaltou que antes mesmo de 1968 o conceito de autogestão era usado por pensadores como Castoriadis e Chauvey para designar uma espécie de democracia industrial, ou seja, autogestão a partir da fábrica. Com o advento dos movimentos sociais de 1968 o conceito foi ressignificado e alargado 
para atender diferentes demandas da sociedade que não só a do operário e da fábrica, em uma forma de autogestão societária (LOCKS; VERONESE, 2012).

A autogestão apareceu como um verdadeiro fator de mudança para seus agentes discursivos e mesmo com as dificuldades e as divergências próprias da utilização do conceito, estes autores representam uma retomada do conselhismo que readaptado ao mundo pós-guerra sugerem uma mudança de foco dentro das teorias socialistas. De um lado, criticam o stalinismo/leninismo, de outro a social-democracia, e por meio de certa idealização da inovadora experiência Iugoslava, preocupavam-se principalmente com as dificuldades de constituição de uma nova sociedade, de suas instituições possíveis e da participação dos agentes dentro destas.

Apesar destes problemas, a defesa de uma democracia radical por parte dos teóricos autogestionários delimita um período no qual as esquerdas parecem redefinir-se com novos pressupostos a partir, não tanto da crítica ao capitalismo, mas principalmente da crítica a modelos estatistas, autoritários e burocráticos de governo. Tendo em vista os insucessos das sociedades pós-revolucionárias e uma análise crítica do socialismo real, o quadro teórico socialista, a partir da década de 1970, começa a repensar a subordinação normalmente submetida aos assuntos políticos em prol das questões econômicas. A defesa da democracia começa então começa a se tornar um valor em si mesmo de acordo com Toledo (1994), confrontando uma nova esquerda "moderna", "reformista", cuja ênfase recai na democracia e na prioridade à política como meio de ação, com uma esquerda "primitiva", "revolucionária" em que a economia ainda se mostra como determinante.

Nesse sentido, a tentativa utópica autogestionária, após tentar se difundir em uma realidade plural pós-68, não se desenvolveu em questões como divulgação e aprimoramento teórico, sendo descartada com a chegada da década de 1980. Para Charbonneau (1993) o conceito caiu em desuso devido à preferência em se discutir aspectos formais da democracia, em contraposição a aspectos de espaços de autonomia. No entanto, mesmo com sua decadência, ainda continuou sendo empregado, embora em menores proporções.

\section{A encruzilhada do final do século XX}

Em paralelo ao desenvolvimento da corrente teórica autogestionária na França, Cunningham (2009) irá afirmar que, devido principalmente aos acontecimentos de maio 
de 68, surge também uma corrente participacionista que irá reivindicar uma ampliação das esferas de participação do Estado na sociedade civil. Um dos marcos para o surgimento desta "nova esquerda" (HELD, 1996) é a publicação de Carole Pateman, em 1970, do livro Participação e Teoria Democrática ${ }^{7}$. Sem um conteúdo tão radical quanto aquele presente nas teorias autogestionárias, a autora irá buscar, nos marcos do capitalismo, inserir organizações participativas na sociedade civil. Com isso, a democracia econômica aparece como um dos grandes temas da teoria participativa, na medida em que reivindica reproduzir o modelo de participação direta no contexto industrial.

Por outro lado, o moderado cientista político Robert Dahl $^{8}$ também irá teorizar uma esfera econômica democratizada inserida em um governo representativo. Em 1985, época de declínio do debate sobre a democracia econômica, Dahl irá escrever o livro Um Prefacio à Democracia Econômica tentando provar a tese de que o moderno sistema de propriedade privada aumenta as desigualdades sociais a ponto de afetar diretamente a liberdade política e, conseqüentemente, o processo democrático. Assim sendo, retoma a crítica feita pelos socialistas do século XIX sobre a propriedade privada contribuir para a criação de grandes diferenças de renda, status, informações, acesso a líderes políticos, e, de modo geral, oportunidades de vida (DAHL, 1985).

Além de problematizar a propriedade individual, também o faz com a propriedade estatal e com a propriedade social, afirmando como melhor solução para este dilema, uma propriedade cooperativa. De tal modo, uma empresa cooperativamente possuída seria simultaneamente pública e privada, pública em relação a seus membros individuais, através de um sistema de quotas, e privada em relação aos seus nãomembros. Na terminologia empregada por Dahl, os funcionários seriam cidadãos da empresa, resolvendo a alocação da renda, seja nos salários, na poupança ou em investimento. Em uma sociedade com empresas autogeridas, não há dúvida, afirma o autor, de que a qualidade da democracia política seria muito superior, tenderia a reduzir os conflitos de interesses, ajudaria na manutenção da igualdade política e das

\footnotetext{
${ }^{7}$ Durante a década de 1960 a participação era vista principalmente em termos eleitorais e gradualmente foram se ampliando as formas de entender o fenômeno. Assim, Pateman (1970), Benjamin Barber e C.B. Macpherson são as principais referências no entendimento da participação política para além das instituições.

${ }^{8}$ Considerado um dos principais cientistas políticos do século XX, é importante destacar sua preocupação tardia com o tema das desigualdades socioeconômicas e da democracia econômica, visto que aparecem em seus livros somente a partir da metade da década de 1980. Até então, obras clássicas como Who Governs, da década de 1960, e Poliarquia: participação e oposição, da década de 1970, estavam centradas eminentemente nas questões procedimentais e institucionais da democracia política.
} 
instituições democráticas. Além disso, a distribuição de renda e riqueza seria menos desigual do que no atual sistema capitalista de propriedade, uma vez que reduziria a diferença entre os salários. No entanto, as desigualdades também existiriam por conta das diferenças nos mercados, das mutações da demanda, razões variáveis entre capital e mão de obra ou diferenças regionais na oferta de trabalho e mão de obra.

Especificamente sobre as formas de organização no local de trabalho, Dahl é enfático ao afirmar que uma assembléia sofreria de todas as debilidades da democracia direta em uma escala excessivamente grande, reproduzindo seu argumento sobre a democracia direta/participativa e o problema das escalas (DAHL, 2001) ${ }^{9}$. Segundo o autor, não se pode esperar que as estruturas administrativas no local de trabalho satisfaçam os critérios do processo democrático em grau nem muito pior, nem muito melhor do que as estruturas democráticas no governo do estado, de modo que um governo representativo teria que ser criado nas empresas para que estas fossem governáveis.

De maneira semelhante, Carole Pateman questiona até que ponto seria possível ter uma situação de democracia direta num contexto econômico, e em que medida os trabalhadores estão interessados e aproveitam as oportunidades de participação oferecidas. Ao contrário de Dahl, que procura justificar os motivos para que uma empresa seja democrática, Pateman busca problematizar o conceito de participação e de democracia dentro das empresas. Dessa forma, a participação só ocorre quando duas ou mais partes influenciam-se reciprocamente na elaboração dos planos, políticas ou decisões e os empregados precisam possuir as informações necessárias sobre as quais possam se basear a sua decisão. Além disso, para ser democrático o governo precisa ser eleito e passível de remoção pelo corpo de empregados, ou em um sistema de democracia direta, todos os trabalhadores precisam tomar decisões administrativas.

Uma vez instaurado este sistema, os teóricos participativos partem do pressuposto que a experiência da participação tornará o indivíduo psicologicamente melhor preparado para participar no futuro. Reforçando o argumento, Pateman baseia-se na constatação de Almond e Verba (1963) de que o individuo, a partir de suas experiências em estruturas de autoridade não-governamentais, teria a tendência de ampliá-las às esferas da política nacional e que as oportunidades para participar no próprio local de trabalho são fundamentais para o desenvolvimento da sensação de

\footnotetext{
${ }^{9}$ Para Dahl (2001) a democracia direta é inviável em contextos nacionais e até mesmo regionais, por conta da complexidade que o processo tomaria ao tentar envolver um número muito alto de indivíduos.
} 
eficácia política. Tendo em vista que a estrutura de autoridade no local de trabalho é provavelmente a mais significativa e notória com a qual um homem está em contato diário (PATEMAN, 1970; ALMOND; VERBA, 1963), a teoria participativa sugere que a própria experiência dessa participação desenvolverá as qualidades necessárias para o bom funcionamento do sistema democrático. Contudo, esses autores ainda são céticos, levando em conta a dificuldade de estabelecer conclusões com os poucos estudos existentes.

Robert Dahl irá criticar a corrente participacionista justamente nesse ponto, por pensar que através de mudanças políticas o ser humano poderá ser regenerado, tornando-se automaticamente mais democrático:

O desenvolvimento humano, o senso de eficácia política, reduzirá a alienação, criará uma comunidade solidária baseada no trabalho, reforçará os vínculos com o bem-estar geral da comunidade, debilitará a influência do auto-interesse, produzirá um conjunto de cidadãos dotados de espírito público, ativos e interessados dentro das empresas, e estimulará maior participação e melhor espírito de cidadania no governo do próprio estado. (DAHL, 1985, p.81).

Portanto, existem algumas diferenças entre ambos os autores no desenvolvimento de uma futura democracia econômica. Embora acreditem que o tema seja de grande importância para o desenvolvimento qualitativo de nossas futuras sociedades em questões como igualdade e liberdade, por um lado, Dahl vislumbra uma democracia representativa tanto nas esferas estatais, quanto nas esferas econômicas, sem problematizar até que ponto esta representação poderia se tornar novamente um despotismo eletivo. Já Pateman, preocupa-se essencialmente com a questão da qualidade democrática dentro das empresas, de modo que todos possam participar de alguma maneira nestas estruturas. No entanto, a conexão que estas empresas socializadas podem ter com uma esfera política também participativa, bem como a questão da transição para tal sistema socializado são perguntas que ficam sem resposta.

David Held (1996), ao analisar as idéias de ambos, irá enfatizar a questão dos limites internos e externos de tais empresas. Seria possível dissolver grandes conglomerados industriais em pequenas empresas para que estas possuam um grau de democracia elevado? Como ficaria a questão do controle e da eficiência das mesmas, uma vez que o mercado exige respostas rápidas e criativas dos empresários? Como seria a relação destas empresas com as estruturas competitivas e predatórias do mercado? Indo mais além, como seria a relação deste mercado com as esferas políticas mais amplas, como as nacionais? Qual seria a relação destas empresas e deste tipo de 
sociedade em uma ambiente internacional diversificado? E para finalizar, como seria efetuada a transição para um sistema desse tipo?

Sem ousar responder todas estas perguntas, visto que este artigo tem apenas o objetivo de problematizar o tema, podemos afirmar que são pontos que se postulam como grandes obstáculos atuais para as teorias preocupadas com os problemas democráticos. É evidente que algumas destas perguntas já possuem algumas respostas possíveis e que podem se encontradas inclusive ao longo deste artigo, enquanto outras ainda necessitam de aprofundamento.

\section{Apontamentos finais de um debate por recomeçar}

O conceito de democracia econômica é polissêmico no discurso dos autores analisados, ora as vestes do cooperativismo e conselhismo, adquirindo um caráter micro, ora de um sistema socializado global. Deste modo, situa-se em um contexto linguístico que surge desde o final do século XVIII e que constitui uma mudança radical com o passado não apenas em termos econômicos, sociais e políticos, mas também cognitivos. As percepções de futuro, passado e presente mudaram desde então; caracterizam um momento sob o qual o "horizonte de expectativa"10 (KOSELLECK, 1993) dos sujeitos históricos se faz presente de maneira mais contundente nos escritos políticos, visto que os conceitos começam a possuir propostas de ativar e reorganizar as massas. Os termos começaram a tornar-se cada vez mais genéricos em suas referências sociais e mais abstratos em seus significados, ganhando assim, a forma linguística de "ismos", como marxismo, liberalismo e republicanismo.

Dentre as mutações que o tema da democracia econômica sofreu, podemos afirmar que, com as propostas dos socialistas utópicos, ela era uma ideia basicamente centrada no cooperativismo e na sua potencialidade, junto de outros mecanismos, de inverter os processos de dominação e hierarquização capitalistas em desenvolvimento no final do século XVIII e início do século XIX. A crítica operada por Karl MarX apontava na direção de que as cooperativas, inseridas em um sistema de mercado, somente amenizavam o grau de hierarquização em relação às empresas capitalistas, sem questionar o sistema como um todo.

10 la expectativa se efectúa en el hoy, es futuro hecho presente, apunta al todavía-no, a lo no experimentado, a lo que solo se puede descubrir. Esperanza y temor, deseo y voluntad, la inquietud pero también el análisis racional, la visión receptiva o la curiosidad forman parte da la expectativa e la constituyen. (Koselleck, 1993, p.338).

Em Debat: Rev. Dig., ISSNe 1980-3532, Florianópolis, n. 12, p. 159-181, jul-dez, 2014. 
Partindo desse debate, no início do século $\mathrm{XX}$ os conselhistas se distanciam ainda mais das ideias cooperativistas e propõem o surgimento de comissões dentro das fábricas que seriam responsáveis pela disseminação de idéias anti-sistêmicas para os trabalhadores. Construindo uma articulação entre comissões, partidos e sindicatos, gradualmente o poder das empresas sairia das mãos dos proprietários, instaurando uma democracia econômica. Com uma nova roupagem, surge na França uma corrente autogestionária que, após os eventos de maio de 1968, é sujeitada a deslocar as propostas de gestão direta das fábricas para a autogestão de todo o corpo social, na tentativa de englobar os novos movimentos sociais que surgiam.

Com o declínio das teorias autogestionárias e, consequentemente, da temática da democracia no âmbito econômico, nos anos finais do século XX dois autores de grande importância para a ciência política contemporânea, Robert Dahl e Carole Pateman, reavivam, ao menos de forma transitória, esse debate. A partir de então, o abandono e a crise das ideias revolucionárias de esquerda, a hegemonia do pensamento liberal acompanhada da crise das democracias formais e o aumento das desigualdades, fizeram com que o foco residisse na constituição de relações econômicas mais justas para um funcionamento mais equilibrado da democracia representativa.

Apesar de termos esse rol de autores de importância inquestionável no pensamento político e social contemporâneo enfatizando a importância e necessidade de uma economia mais democrática, a idéia em si não conseguiu triunfar ao longo destes dois séculos. Negligenciada em prol do debate sobre questões procedimentais da democracia política, como reivindicava Giovanni Sartori no inicio deste artigo, pudemos perceber suas mutações, relacionadas ao desenvolvimento das relações produtivas e sócio-econômicas. Tendo em vista tanto o acúmulo de conhecimento teórico e empírico sobre a importância de relações mais democráticas no âmbito econômico, quanto os problemas socioeconômicos enfrentados no atual estágio do desenvolvimento capitalista, cabe nos perguntarmos sobre a necessidade de resgatar e situar esse debate no século XXI. 


\section{BIBLIOGRAFIA}

ABENDROTH, Wolfgang. A história social do movimento trabalhista europeu. Rio de Janeiro: Paz e Terra, 1977.

ALBORNOZ, Suzana Guerra. Atração passional, trabalho e educação em O novo mundo industrial e societário de Charles Fourier. Cadernos de Psicologia Social do Trabalho, 2007, vol. 10, n. 1, p. 1-19.

ALMOND, Gabriel; VERBA, Sidney. The Civic Culture: Political Attitudes and Democracy in Five Nations. Princeton: Princeton UP, 1963.

BOBBIO, Norberto. Teoria geral da política: a filosofia política e as lições dos clássicos. Rio de Janeiro: Campus, 1995.

CASTORIADIS, Cornelius. Figuras De Lo Pensable: Las Encrucijadas Del Laberinto Vi. Buenos Aires: Fondo de Cultura Economica de Argentina, 2001.

CHARBONNEAU, Daniel. Développement du discours autogestionnaire dans la pensée sociale contemporaine en France(1960-1980). Tese de doutorado, University of Ottawa, 1993.

COUTINHO, Carlos Nelson. A dualidade de poderes: Estado e revolução no pensamento marxista. In: A dualidade de poderes e outros ensaios. São Paulo: Cortez, 1994.

CUNNINGHAM, Frank. Teorias da Democracia - uma introdução crítica. Porto Alegre: Editora Artmed, 2009.

DAHL, Robert A. Um prefácio à democracia econômica. Rio de Janeiro: Jorge Zahar, 1985.

Robert A. Sobre a democracia. Brasília: UnB, 2001.

FOLLIS, Massimo. Autogestão. In: BOTTOMORE, Tom (org). Dicionário do pensamento marxista. Rio de Janeiro: Jorge Zahar Editor, 2001. 
FRIEDMANN, Georges; NAVILLE, Pierre. Traité de sociologie du travail. Paris: Armand Colin, 1962.

GERBER, John. Anton Pannekoek and the Socialism of Workers' SelfEmancipation, 1873-1960. Dordrecht: Kluwer Academic Publishers, 1989.

GUILLERM, Alan; BOURDET, Yvon. Autogestão: Mudança Radical. Rio de Janeiro: Zahar, 1976.

GRAMSCI, Antonio. Escritos Políticos. México: Siglo XXI, 1999. Antonio. Democracia operária. Coimbra: Centelha, 1976.

Antonio El instrumento de trabajo. LON, 1920. Disponível em:

<http://www.gramsci.org.ar $>$.

HAIDAR, Julieta. Gramsci y los consejos de fábrica. Discusiones sobre el potencial revolucionario del sindicalismo. Núcleo Básico de Revistas Científicas Argentinas del CONICET, $N^{\circ}$ 15, vol. XIV, 2010.

HELD, David. Models of democracy. English: Published Oxford, 1996.

HIRST, Paul. A democracia representativa e seus limites. Rio de Janeiro: Zahar, 1992.

JACKSON, J. Hampden. Marx, Proudhon e o socialismo europeu. Rio de Janeiro: Zahar, 1963.

KONDER, Leandro. Fourier, o socialismo do prazer. Rio de Janeiro: Civilização Brasileira, 1968.

KOSELLECK, Reinhart. Futuro pasado: Para una semantica de los tiempos historicos. Buenos Aires: Paidos, 1993.

LOCKS, Pompilio; VERONESE, Marília. Tramas Conceituais: uma análise do conceito de autogestão em Rosanvallon, Bourdet e Guillerm. Política \& Trabalho (UFPB. Impresso), v. 36, p. 267-290, 2012. 
MARX, Karl. Manifesto de lançamento da AIT. IN: MARX, Karl, ENGELS, Friedrich. O Manifesto do Partido Comunista. São Paulo: Editora Martin Claret, 2004.

MASSARI, Roberto. Teorias de la Autogestión. Madrid: Zero, 1977.

MERLO, Álvaro Roberto Crespo; LAPIS, Naira Lima. A saúde e os processos de trabalho no capitalismo: reflexões na interface da psicodinâmica do trabalho e da sociologia do trabalho. Psicologia \& Sociedade, 19 (1), 61-68, 2007.

MOTHÉ, Daniel. L'Autogestion goutte à goutte. Paris: Éditions du Seuil, 1980; GURVITCH, Georges. Extraits de l'Oeuvre. Autogestion, ètudes, débats, documents. Paris: Cahier no. 1, décembre, 1966.

MOTTA, Fernando Prestes. Burocracia e Autogestão: Proposta de Proudhon. São Paulo: Brasiliense, 1981.

PANNEKOEK, Anton. Os Conselhos Operários. Coimbra, Centelha, 1976.

PATEMAN, Carole. Participação e teoria democrática. Rio de Janeiro: Paz e Terra, 1970.

PINTO, Geraldo Augusto. A organização do trabalho no século XX: taylorismo, fordismo e toyotismo. São Paulo: Expressão Popular, 2007.

RIQUELME, Sergio Fernàndez. Sobre los orígenes de la Democracia social: Henri de Saint-Simon y Louis Blanc. Corporativismo y política social en el siglo XIX. Anales de Historia Contemporánea, n. 25, 2009.

ROSANVALlON, Pierre. La Autogestión. Madrid; Editorial Fundamentos, 1979.

SANTOS, Boaventura de Sousa; AVRITZER, Leonardo, "Para ampliar o cânone democrático", in Santos, Boaventura de Sousa (org.), Democratizar a Democracia. Os caminhos da democracia participativa. Porto: Afrontamento, 2002.

SARTORI, Giovanni. Qué es la democracia?. Buenos Aires: Taurus, 2003. 
SECCO, Lincoln. Cooperativas e Conselhos Operários. São Paulo: Lutas Sociais (PUCSP), v. 9/10, p. 169-178, 2003.

SCHUMPETER, Joseph. Capitalismo, socialismo e democracia. Rio de Janeiro: Fundo de cultura, 1961.

TOLEDO, Caio Navarro de. A modernidade democrática: adeus à revolução? . Revista Crítica Marxista, São Paulo, nº1, p. 27-38, 1994.

TSUZUKI, Chushichi (Editor). Robert Owen and the world of co-operation. Japan: Robert Owen Association of Japan, 1992.

VIANA, Nildo. O Marxismo Libertário de Anton Pannekoek. Revista Espaço Acadêmico, $\mathrm{N}^{\circ}$ 48, Maio/2005. 